\title{
Electrodeposited Metal Organic Framework towards Excellent Hydrogen Sensing in an Ionic Liquid
}

\author{
Muhammad Rizwan Azhar ${ }^{\mathrm{a}, \mathrm{b} \dagger}$, Ghulam Hussain ${ }^{\mathrm{c}, \mathrm{d}, \dagger}$, Moses O. Tade ${ }^{\mathrm{a}}$, Debbie S. Silvester ${ }^{\mathrm{r}^{*}}$, \\ and Shaobin Wang ${ }^{\mathrm{a}, \mathrm{e}^{*}}$
}

${ }^{a}$ Department of Chemical Engineering, Curtin University, GPO Box U1987, Perth, WA 6845, Australia

${ }^{\mathrm{b}}$ Present address: School of Engineering, Edith Cowan University, 270 Joondalup drive, WA 6025, Australia

${ }^{c}$ Curtin Institute for Functional Molecules and Interfaces, School of Molecular and Life Sciences, Curtin University, GPO Box U1987, Perth, WA 6845, Australia

d Department of Chemistry, KTH Royal Institute of Technology, 10044, Stockholm, Sweden.

e School of Chemical Engineering and Advanced Materials, The University of Adelaide, Adelaide, SA 5005, Australia

*Corresponding Authors: Shaobin.wang@adelaide.edu.au

D.Silvester-Dean@curtin.edu.au

${ }^{+}$These authors contributed equally to this work.

\begin{abstract}
The synthesis of thin films of metal organic frameworks (MOFs) is a rapidly growing area owing to the use of these highly functional nanomaterials for various applications. In this study, a thin layer of a typical MOF, copper benzene tricarboxylate (HKUST-1), was synthesized by electrodeposition on a glassy carbon (GC) electrode using a potential-step chronoamperometric technique at room temperature. Various characterization techniques including Fourier transform infrared (FTIR) spectroscopy, X-ray diffraction (XRD), scanning electron microscopy (SEM) and X-ray photoelectron spectroscopy (XPS) were used to verify the successful deposition of the MOF film and its structure. The electrodeposited MOF crystals showed cuboctahedral morphology with macropores. The MOF-modified electrode was applied for hydrogen gas sensing in a room temperature ionic liquid (RTIL) for the first time. A four-fold increase in current was observed compared to a precious metal surface, i.e. platinum, and the electrode exhibited significant catalytic activity compared to the bare GC electrode, making it a very promising low cost material for hydrogen gas sensing applications.
\end{abstract}


Keywords: Thin films, electrodeposition, MOFs, ionic liquids, electrochemistry, hydrogen oxidation.

\section{Introduction}

Hydrogen is one of the most promising fuels for a greener environment. However, its explosive nature makes it dangerous when mixed in air at concentrations of $4-75 \%$ by volume, and it can be easily ignited. Hydrogen is one of the lightest compounds with a relative density of 0.07 and can be accumulated near the ceiling of an airtight room. High concentrations of hydrogen can cause asphyxiation by the exclusion of oxygen ${ }^{1}$. Therefore, the detection of any leaks of hydrogen is of utmost importance to ensure safety. Different strategies have been employed to detect hydrogen, including catalytic, thermal conductivity, resistance, work function, mechanical, optical, acoustic and electrochemical sensing. ${ }^{1-2}$ Recent studies reported metal based semiconducting nanowires doped with Pd nanoparticles and metal organic framework (MOF) derived metal oxides with Pd composites for the detection of hydrogen. ${ }^{3}$ The developed composite showed good selectivity and sensitivity towards hydrogen detection. However, the synthesis method involved multiple steps and use of a precious metal, Pd. Another study reported Pd decoration of graphene for hydrogen detection at $1000 \mathrm{ppm}$ in a hydrogen stream ${ }^{4}$. In addition, Pt modified electrodes have also been widely explored for the detection of hydrogen, and other gases like oxygen and ammonia in recent years. ${ }^{5-8}$

MOFs are a new class of functional porous materials with inorganic and organic species arranged in a regular pattern ${ }^{9-12}$. The inorganic component in MOFs is usually a metal or metal oxide node, and the organic part is a multidentate ligand such as a benzene carboxylic acid. The metal and ligand can be arranged in specific patterns to form one dimensional (1D), two dimensional (2D) and three dimensional (3D) nanoporous materials. Thus, countless numbers of MOFs can be synthesized using different metal and organic linkers. ${ }^{13-15}$ Generally, MOFs are synthesized as powders using solvo/hydrothermal techniques at elevated temperatures and high pressure. Such synthesis techniques require the extensive use of chemicals and specific activation techniques (e.g. solvent extraction and heating), which may take up to several days. ${ }^{16-18}$ In recent years, MOFs have attracted attention in thin film coatings, owing to their tunable properties and ease of synthesis even at room temperature ${ }^{19-22}$. Various methods of thin film formation of MOFs have been reported such as the dipping method by exposing substrates to precursor solutions ${ }^{23}$, chemical vapor deposition $(\mathrm{CVD})^{20}$, anodic dissolution ${ }^{21}$ and cathodic electrodeposition ${ }^{24}$. Fabrication of such coatings can be used for catalysis ${ }^{25}$, 
microelectronics, separation ${ }^{22}$ and sensing ${ }^{26-27}$. However, the synthesis parameters ${ }^{28-29}$ play an important role in the final form of the synthesized thin films of $\mathrm{MOFs}^{30}$.

Recently, CVD synthesis ${ }^{20}$ of zeolitic imidazole framework-8 (ZIF-8) was reported in a twostep process where metal oxide layers were fabricated in the first step, and later dissolution of the metal resulted in formation of a ZIF-8 thin film in the presence of an organic linker (2methyle imidazole). Similarly, a series of ZIFs have been studied using anodic dissolution with $\mathrm{Co}$ and $\mathrm{Zn}$ electrodes for supercapacitors ${ }^{31}$. A more detailed study on the synthesis mechanism has been reported using anodic synthesis ${ }^{21}$ of copper benzene tricarboxylate, also known as HKUST-1 (Hong Kong University of Science and Technology-1) on glassy carbon (GC). In contrast to the two-step methods (CVD and anodic dissolution), another viable process for fabrication of MOF thin films is a cathodic electrochemical deposition, which takes place in a single step with or without using a pro-base. ${ }^{19,24}$ In the pro-base synthesis route, precursor solutions are simultaneously used in one step by tuning the synthesis parameters such as the precursor ratio, $\mathrm{pH}$, pro-base material and applied voltage. The role of a pro-base is to facilitate deprotonation of the organic linker, which further coordinates with metal nodes to form a framework ${ }^{24}$. On the other hand, in a non-pro-base synthesis procedure, in-situ generation of hydroxyl ions results in the deprotonation of the organic linker such as benzene tricarboxylic acid (BTC). Moreover, the introduction of a surfactant can help tune the structure of the MOF and control the porosity of the final product ${ }^{19,32}$. This hypothesis was confirmed in a recent study where thin films of ZnBTC MOF were synthesized on different electrodes using cathodic deposition with cetyltrimethylammonium bromide (CTAB) as a surfactant without any probase $^{19}$.

In this study, cathodic deposition is used to electrodeposit HKUST-1 on a GC electrode from dilute precursor solutions to avoid an excessive use of chemicals, which is common in bulk powder synthesis of MOFs. There are several reports on the chemical synthesis of pure MOF materials and MOF-based composites for applications as electrochemical probes for the detection of organic/biological molecules, pathogens, gases etc. ${ }^{33-36}$ However, most of these studies focused on MOF-derived materials and there are few studies on the direct use of pure MOFs for electrochemical applications, e.g. lithium-ion/sulfur batteries, zinc-air batteries, electrocatalytic water splitting and electrochemical sensing ${ }^{37}$.

To the best of our knowledge, no report is available on electrochemical hydrogen sensing using electrodeposited pristine MOFs in room temperature ionic liquids (RTILs). RTILs possess 
highly functional moieties and show excellent properties as an electrolyte material for ammonia and hydrogen sensing on precious metal electrodes (e.g. Pt). ${ }^{6,8}{ }^{38}$ In most cases, only a very small quantity of RTILs is needed, which reduces the overall cost of the sensor. In this work, we demonstrate that a MOF modified electrode shows excellent catalytic properties compared to a glassy carbon electrode for hydrogen sensing, and even shows higher currents compared to an ideal platinum surface. This paves the way for the use of electrodeposited MOFs as enhanced electrode materials for a wide range of sensing applications.

\section{Experimental}

2.1 Chemical Reagents. All chemicals were commercially available and used as received. Absolute ethanol (EtOH, $\geq 99.8 \%$ ), acetone ( $>99 \%$ ), hydrochloric acid (37\% w/w), copper (II) nitrate trihydrate $\left(\mathrm{Cu}\left(\mathrm{NO}_{3}\right)_{2} \bullet 3 \mathrm{H}_{2} \mathrm{O}, \geq 99 \%\right)$, sodium nitrate $\left(\mathrm{NaNO}_{3}, \geq 99.9 \%\right)$, trimesic acid $\left(\mathrm{C}_{6} \mathrm{H}_{3}\left(\mathrm{CO}_{2} \mathrm{H}\right)_{3}, 95 \%\right)$, and cetyltrimethylammonium bromide (CTAB, $\left.\geq 99 \%\right)$ were obtained from Sigma-Aldrich. The room temperature ionic liquid (RTIL) 1-ethyl-3-methylimidazolium bis(trifluoromethylsulfonyl)imide $\left(\left[\mathrm{C}_{2} \mathrm{mim}\right]\left[\mathrm{NTf}_{2}\right]\right)$, was purchased from Merck (Kilsyth, Victoria, Australia) at ultra-high purity of electrochemical grade (>99\%). Ultrapure water with a resistance of $18.2 \mathrm{M} \Omega \mathrm{cm}$ was prepared by an ultrapure water purification system (Millipore Pty Ltd., Australia). Acetone was used for washing the electrodes before and after use. An ethanol/ultrapure water mixture (1:1) was used to stabilize the electrodeposited MOFs. Ferrocene $\left(\mathrm{Fe}\left(\mathrm{C}_{5} \mathrm{H}_{5}\right)_{2}, \mathrm{Fc}, 98 \%\right.$, Sigma-Aldrich) and cobaltocenium hexafluorophosphate $\left(\left[\mathrm{Co}\left(\mathrm{C}_{5} \mathrm{H}_{5}\right)_{2}\right] \mathrm{PF}_{6}, \mathrm{Cc}^{+}\right.$, Acros Organics, 98\%) were used as received. Hydrogen $(99.99 \%)$ and nitrogen gases ( $\geq 99.99 \%$ ) were purchased from BOC gases, Australia.

2.2 Plating Bath Preparation. For the preparation of the plating bath, $4.5 \mathrm{mmol}(11.8 \mathrm{mg})$ of copper nitrate trihydrate and $100 \mathrm{mmol}(85 \mathrm{mg})$ of sodium nitrate were dissolved in $10 \mathrm{~mL}$ ultrapure water to prepare solution S1. Similarly, $2.5 \mathrm{mmol}(5.2 \mathrm{mg})$ of benzene tricarboxylic acid (BTC) as an organic ligand and $2.7 \mathrm{mmol}(9.8 \mathrm{mg})$ of CTAB surfactant as a structuredirecting agent were dissolved in $10 \mathrm{~mL}$ absolute ethanol to prepare solution $\mathrm{S} 2$. Both the solutions were sonicated for $10 \mathrm{~min}$ and then stirred for another $15 \mathrm{~min}$ to ensure complete dissolution of the chemicals. Then solution S2 was added into solution S1 under fast magnetic stirring. Prior to starting the electrodeposition process, the resulting plating bath was then aged under vigorous stirring for $30 \mathrm{~min}$ after adjusting the $\mathrm{pH}$ to $2.0 \pm 0.2 \mathrm{using} 50 \% \mathrm{HCl}$. An acidic 
$\mathrm{pH}$ of 2 favors the deprotonation of the organic ligand (trimesic acid), which is required to synthesize the MOF on the electrode surface.

2.3 Electrochemical Experiments All experiments were performed using a PGSTAT101 Autolab potentiostat (Eco, Chemie, Netherlands) interfaced to a PC with Nova 1.11.2 software, at room temperature inside an aluminium Faraday cage in a fume cupboard. The glassy carbon (GC) and platinum (Pt) 'change-disk' working electrodes were both $5 \mathrm{~mm}$ in diameter and 4 mm thick (PINE Research Instrumentation Inc., Durham, NC, USA). The removable electrodes were inserted into a hollow disk of PTFE to define the electrode area. Prior to use, the electrodes were polished on soft lapping pads (Buehler, Illinois, USA) with decreasing size of alumina (3, 1 and $0.5 \mu \mathrm{m}$, Kemet, NSW, Australia), and then sonicated in acetone and ultrapure water for 15 min each.

For electrodeposition experiments, a conventional three-electrode cell was employed: the GC stub as a working electrode, $\mathrm{Ag} / \mathrm{AgCl}$ as a reference electrode $(0.1 \mathrm{M} \mathrm{KCl}, \mathrm{BASi}$, Indiana, USA) and Pt coil as a counter electrode (Goodfellow, UK). All the electrodes were suspended into a home-made glass cell containing 3-5 $\mathrm{mL}$ plating bath solution. The deposition of HKUST-1 was achieved by following a facile electrochemical method reported in the literature ${ }^{19}$ with some modifications, as detailed later.

The experiment started from the open circuit potential, then the potential was held at $-1.4 \mathrm{~V}$ (vs external $\mathrm{Ag} / \mathrm{AgCl}_{(\mathrm{aq})}$ reference electrode) for $2 \mathrm{~h}$. After the deposition was completed, the modified electrode was removed gently from the electrochemical cell and soaked in ultrapure water to remove any surfactant or plating solution components. The thin-film of HKUST-1 layer was aged in a solution of 50\% ethanol/water mixture under moderate stirring for $60 \mathrm{~min}$ to ensure complete extraction of the surfactant template. Finally, the electrodeposited thin film of HKUST-1 was activated by placing the modified GC electrode into an oven for $30 \mathrm{~min}$ at an elevated temperature of $100-140^{\circ} \mathrm{C}$. A short time of heating was selected due to the very thin film of HKUST-1, which was sufficient to evaporate all remaining solvent. A higher temperature $\left(140^{\circ} \mathrm{C}\right)$ and longer time $(4 \mathrm{~h})$ of heating were also carried out to ensure a complete removal of loosely bound solvent molecules, but there was very little difference in the behavior of the deposited sample ${ }^{17}$. After electrodeposition of HKUST-1, the electrode was covered and stored in a desiccator under vacuum in a temperature-controlled laboratory $\left(21 \pm 1{ }^{\circ} \mathrm{C}\right)$. The modified electrode was found to be stable and can be used after a month with reproducible results (currents within 5\%). 
To test the activity of the electrodeposited MOF material for hydrogen oxidation, the HKUST-1 on GC electrode was housed in a custom-made electrochemical cell provided by the supplier (PINE Research Instrumentation Inc.). For gas experiments, the disk core assembly with the HKUST-1 on GC was inserted into a PTFE holder and tightened with a disk core nut. The RTIL [ $\left.\mathrm{C}_{2} \mathrm{mim}\right]\left[\mathrm{NTf}_{2}\right]$ at $300 \mu \mathrm{L}$ was added into the cavity of the PTFE holder to ensure that all the three electrodes were immersed in the RTIL. Finally, the PTFE holder with the HKUST -1 on GC working electrode was inserted into the bottom of a modified glass T-cell. ${ }^{39}$ The top of the cell was closed with a PTFE stopper containing a Pt coil counter electrode and an Ag wire quasi-reference electrode, suspended into the ionic liquid. Prior to the introduction of hydrogen gas, the cell was purged with nitrogen to remove dissolved gases and impurities from the RTIL. When the baseline was stable (after ca. $60 \mathrm{~min}$ ), hydrogen gas was introduced into the cell and continuously flowed over the electrode at a flow rate of 300 standard cubic centimeters per minute ( $\mathrm{sccm})$, using a gas mixing rig as reported previously. ${ }^{40-41}$

2.4 Characterization. Powdered X-ray diffraction (PXRD) profiles were recorded in a range of $2 \theta=5-70^{\circ}$ on a diffractometer D8 Advance (Model Bruker aXS) using $\mathrm{Cu} \mathrm{K} \alpha$ radiation $(\lambda=1.5418 \mathrm{~nm})$. Infrared spectra were obtained using a Fourier transform infrared (FTIR) spectrometer (Model 100-FT-IR) from Perkin-Elmer) for determining functional groups and linkage between metal nodes and organic linkers. Scanning electron microscopy (SEM) was performed using a Zeiss NEON 40 EsB CrossBeam for morphological analysis of HKUST-1 thin films. Atomic force microscopy (AFM) was performed using a WITech alpha 300SAR to estimate the thickness of the electrodeposited thin film of HKUST-1 on the GC electrode. Xray photoelectron spectroscopy (XPS) was performed on a Kratos AXIS Ultra DLD system under an ultrahigh vacuum atmosphere $\left(1 \times 10^{-9} \mathrm{mBar}\right)$. All elements were calibrated by setting the dominant $\mathrm{C} 1 \mathrm{~s}$ peak at $284.5 \mathrm{eV}$. The measurements were carried out under a charge neutralizer to overcome the charging of the sample. Moreover, the peaks were fitted with Shirley background and quantified using CasaXPS software ${ }^{18}$.

\section{Results and Discussion}

\subsection{Electrochemical Deposition and Characterizations of HKUST-1. A facile} electrochemical route was adopted to synthesize HKUST-1 (see Fig. 1). In a typical synthesis, the inorganic phase solution (S1) was prepared in ultrapure water, while the organic phase solution (S2) containing BTC and CTAB was prepared in absolute ethanol. After complete dissolution of the organic and inorganic precursors, mixing of the solutions was carried out and 
subsequently, electrochemical synthesis of HKUST-1 was performed on the mixture after adjusting the solution $\mathrm{pH}$ to 2.0. Previous literature of cathodically deposited ${ }^{21}$ HKUST-1 shows that the first step is the nucleation of dispersed nuclei, where $\mathrm{Cu}^{2+}$ is reduced to $\mathrm{Cu}^{0}$ on the substrate surface, but at the same potential (-1.0 V) HKUST -1 formation also occurs due to a shift of solution $\mathrm{pH}$ in the proximity of the electrode surface as a result of hydrogen evolution. This shifts the equilibrium and triggers the deprotonation of trimesic acid, resulting in the formation of a MOF island. When an overpotential of $-1.4 \mathrm{~V}$ is applied, electrodeposition of HKUST -1 is more favorable compared to copper deposition, which results in the production of rough and uneven MOF crystals ${ }^{21}$.

In a typical solvothermal/hydrothermal synthesis, deprotonation of organic ligands is the major step, which takes place at elevated temperatures and high pressures. However, in cathodic electrochemical synthesis, the in-situ generation of $\mathrm{OH}^{-}$ions play an imperative role in deprotonation of the $\mathrm{BTC}$, which is also facilitated by $\mathrm{NO}_{3}{ }^{-}$. Similarly, water acts as both the solvent and provider of hydroxyl ions. This process takes place near the surface of the electrode, so an increase in $\mathrm{pH}$ occurs only at the interface and not in the bulk solution. Also, water being a protic solvent prevents metal deposition on the surface of the working electrode due to efficient hydrogen evolution ${ }^{21}$. Surfactants provide enhanced wettability through electrostatic interactions and direct the negatively charged BTC ligands towards the electrode surface, where coordination of $\mathrm{Cu}^{2+}$ and deprotonated BTC takes place, resulting in the formation of a HKUST-1 MOF ${ }^{19}$. CTAB is a structure directing agent because it is cationic, and interacts with negatively charged deprotonated BTC through electrostatic interactions on the electrode surface. The CTAB is then removed by activation of the electrodeposited MOF with an ethanol/water mixture under moderate stirring, which affects the porosity of the deposited $\mathrm{MOF}^{19}$.

Previous literature reveals that the electrodeposition of HKUST-1 occurs in two layers; a top thick layer of octahedral MOF crystals, and bottom thin adherent layer (composed of both copper deposits and MOF deposits) due to the co-deposition method ${ }^{21}$. The mechanism involves initial growth of the MOF in a thin layer, which is controlled by the applied voltage at the GC electrode. Further growth then continues through a MOF island and inter layer growth. At a later stage in the deposition, intergrowth of the film becomes significant, hence, the growth is a combination of both the applied voltage and seed-mediation. The formation of discrete copper nanoparticles during electrodeposition is unlikely to occur at the overpotential 
applied (-1.4 V vs $\mathrm{Ag} / \mathrm{AgCl})$. Furthermore, XPS analysis does not reveal any peaks of metallic copper, ${ }^{21}$ as shown later.
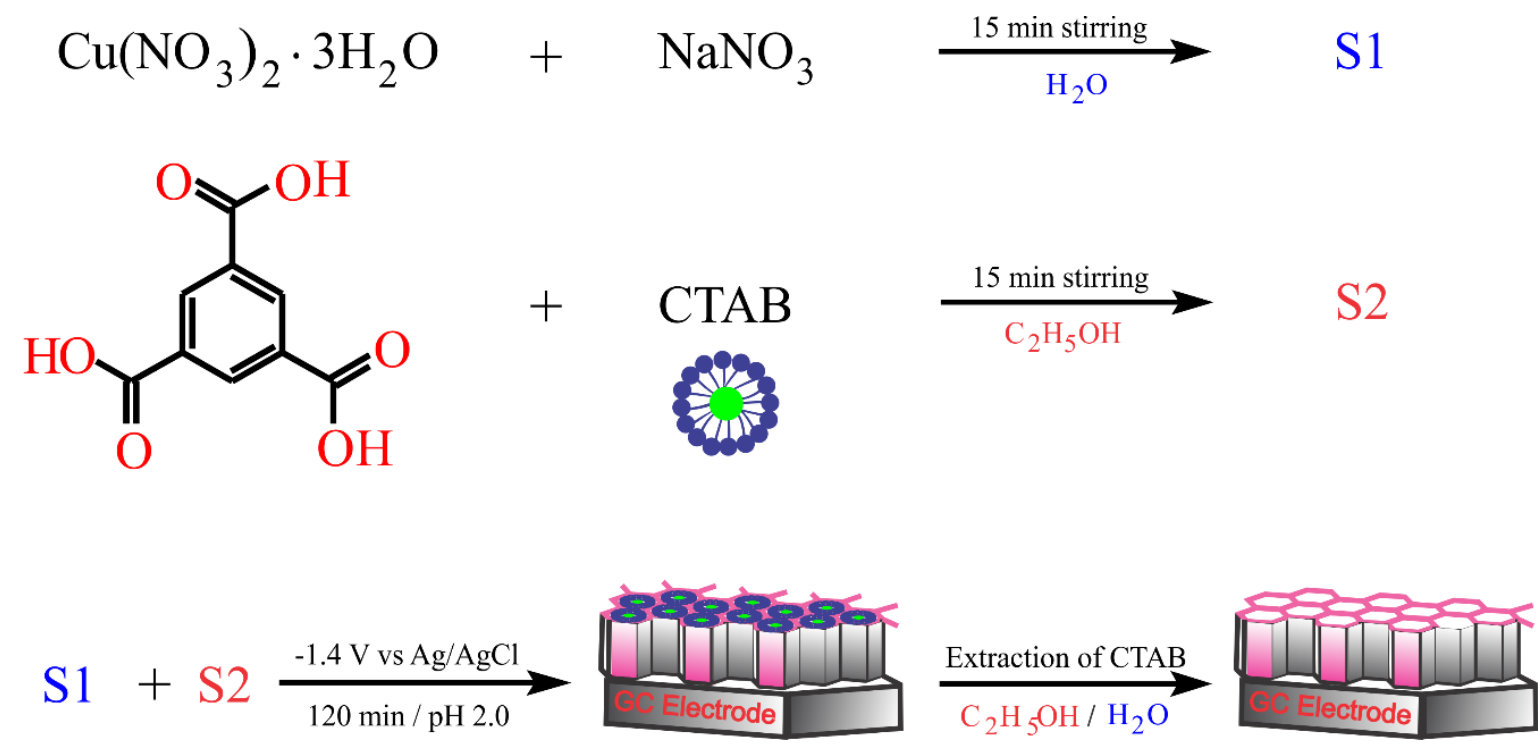

Figure 1. Illustration of the steps involved in the electrodeposition of HKUST-1 on a glassy carbon (GC) electrode.

The coordination of copper and the organic linker is verified through FTIR analysis (Fig. 2a). It can be seen that a sharp peak at $733 \mathrm{~cm}^{-1}$ indicates bonding between copper and oxygen of $\mathrm{BTC}^{16}$. Moreover, two sharp peaks at $1370 \mathrm{~cm}^{-1}$ and $1649 \mathrm{~cm}^{-1}$ show $\mathrm{C}=\mathrm{C}$, and asymmetric stretching due to the presence of COO, respectively. The absence of a broad peak at 3000$3500 \mathrm{~cm}^{-1}$ indicates a water-free structure of the synthesized MOF, which is usually present in bulk synthesis ${ }^{42}$. However, a small peak appears at ca. $3600 \mathrm{~cm}^{-1}$ corresponding to an isolated $\mathrm{OH}$ band, which could be due to a small amount of water adsorbed by the MOF film while handling the sample, since HKUST-1 is known to be hygroscopic in nature ${ }^{16}$. Also, there is no peak at $1700 \mathrm{~cm}^{-1}$, indicating complete deprotonation of $\mathrm{BTC}^{18}$. This deprotonation is imperative in linking metal nodes and BTC linkers. 
FTIR

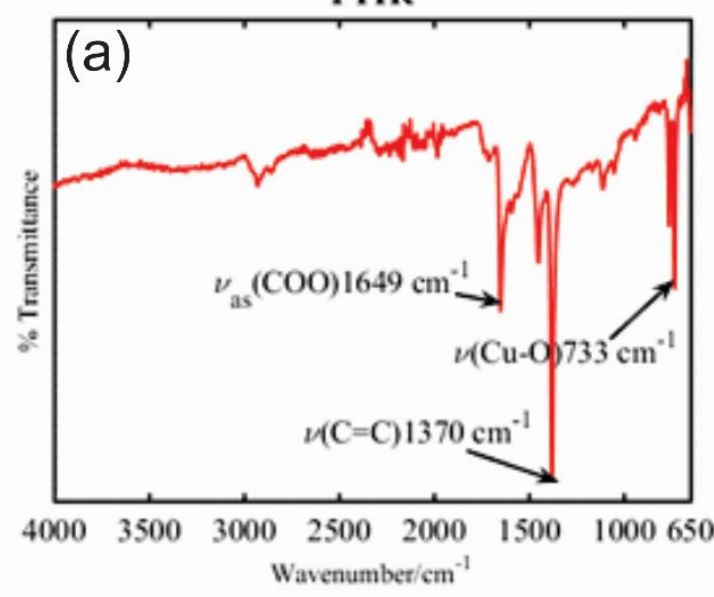

O 1s

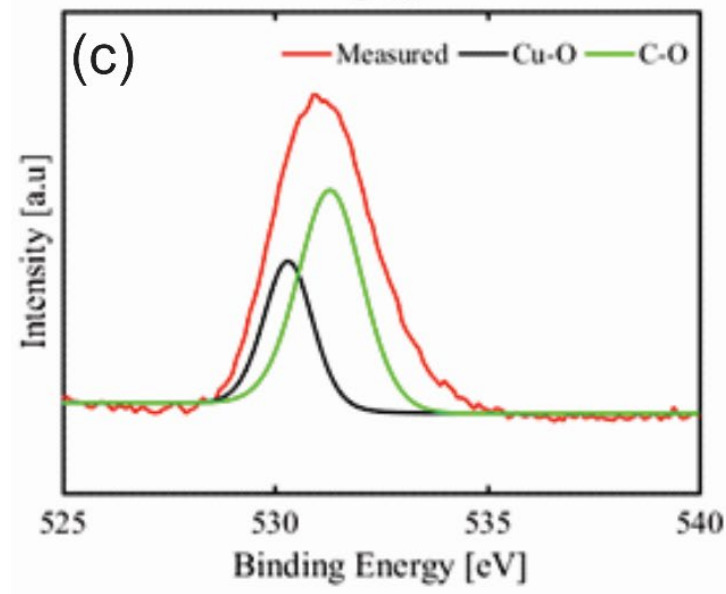

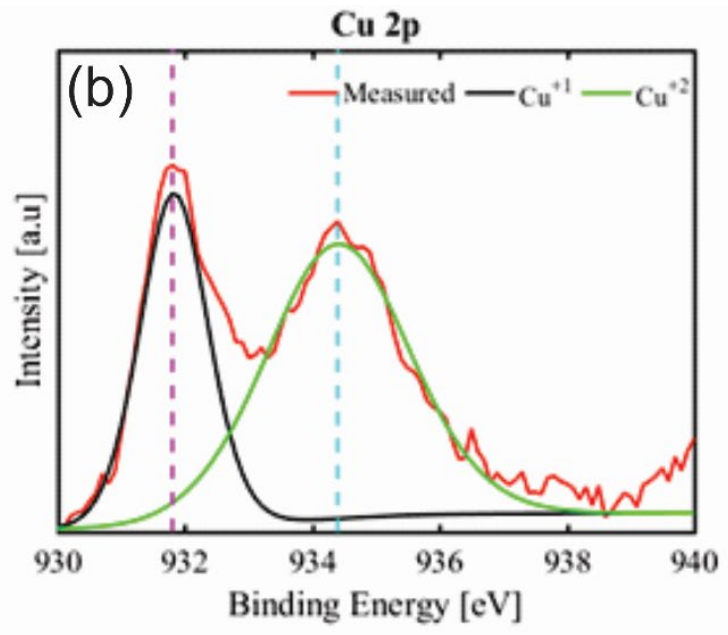

C 1s

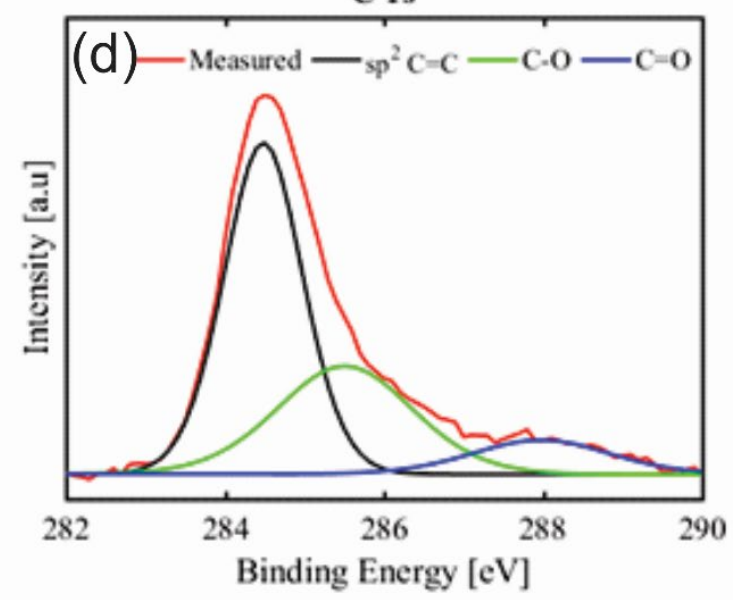

Figure 2. Characterizations of electrodeposited HKUST-1 on GC electrode, (a) FTIR, (b) high resolution XPS Cu 2p, (c) O 1s XPS, and (d) high resolution C 1s XPS spectra.

XPS analysis is a useful technique to study the oxidation states of various constituents of compounds and verify the FTIR results. XPS data were collected with a step size of $0.06 \mathrm{eV}$ and dwell time of $600 \mathrm{~s}$ for $\mathrm{O}(1 \mathrm{~s}), \mathrm{C}(1 \mathrm{~s})$ and $\mathrm{Cu}(2 \mathrm{p})$. XPS measurements were carried out using a charge neutralizer, which is a common practice when analyzing MOFs, to overcome any charging of samples ${ }^{43} . \mathrm{Cu}(2 \mathrm{p})$ spectra showed two distinct peaks at 932.5 and $935 \mathrm{eV}$ (Fig. $2 b)$, revealing the presence of $\mathrm{Cu}(\mathrm{I})$ and $\mathrm{Cu}(\mathrm{II})$ in HKUST-1 on GC. These peaks match the binding energies of $\mathrm{Cu}_{2} \mathrm{O}$ and $\mathrm{CuO}$, confirming that the oxidized forms of copper are present in the electrosynthesized HKUST-1 on $\mathrm{GC}^{44}$. However, these peaks likely do not belong to copper oxide(s) impurities, since mixed oxidation states i.e. $\mathrm{Cu}(\mathrm{I})$ and $\mathrm{Cu}(\mathrm{II}) \mathrm{HKUST}-1$ on GC can exist ${ }^{45}$ without losing the structural integrity. An earlier study on tracking unsaturated metal sites in a HKUST-1 MOF reported a similar pattern, indicating the presence of these useful functionalities in our electrochemically synthesized HKUST-1. The availability of unsaturated metal sites has been found to be very effective in the adsorptive removal of electron 
donor species ${ }^{16}$ and such active sites are very helpful in electrochemical applications ${ }^{46}$. Further resolution of the $\mathrm{O}(1 \mathrm{~s})$ and $\mathrm{C}(1 \mathrm{~s})$ spectra (Fig. 2c and Fig. 2d) confirm the oxidation state of copper and its coordination with the BTC linkers. In particular, fitting of the $\mathrm{O}(1 \mathrm{~s})$ spectra at $530.1 \mathrm{eV}$ shows oxygen bonding to copper, while a binding energy of $531.2 \mathrm{eV}$ corresponds to a carbonate type of bonding, reinforcing the presence of $\mathrm{COO}$ in the MOF structure. Furthermore, carbon high resolution spectra show the bonding of carbon with oxygen $(\mathrm{C}=\mathrm{O}$ and $\mathrm{C}-\mathrm{O}$ ), and the bonding of carbon with carbon. Thus the XPS results reinforce these observations ${ }^{47}$.
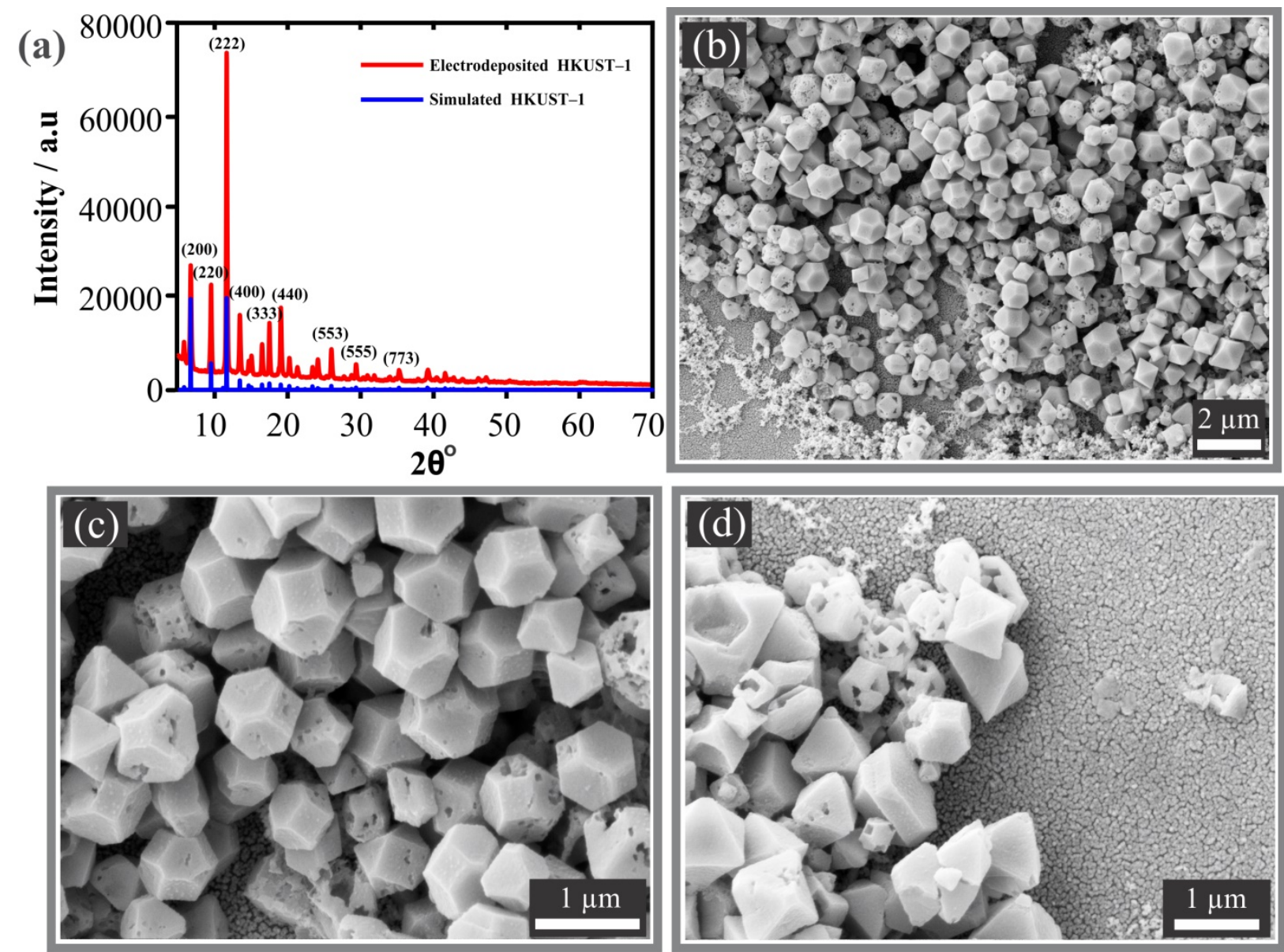

Figure 3. (a) XRD and (b) scanning electron microscopy (SEM) images for electrodeposited HKUST-1 on GC electrode, upon applying a constant potential of $-1.4 \mathrm{~V} \mathrm{vs.} \mathrm{Ag} / \mathrm{AgCl}$ for 7200 $\mathrm{s}$. The average diameter of the chamfered cubes is $855 \pm 65 \mathrm{~nm}$. Figure (b) shows slightly zoomed-out image and Figures (c-d) show zoomed-in images at different locations on the electrode.

After verification of the successful synthesis of HKUST-1 on GC through electrochemical deposition, the crystallinity of the MOF was studied by XRD. HKUST-1 on GC electrode possesses crystalline phases that are similar to previously reported results ${ }^{16,26,48}$. The XRD pattern (Fig. 3a) confirms the successful synthesis of the MOF on the GC electrode. 
Electrodeposited HKUST-1 has a cubic crystal structure with a space group (Fm $\overline{3} \mathrm{~m})$. XRD peaks corresponding to the reflection planes are indexed accordingly ${ }^{48}$. Wider peaks in the XRD pattern indicate that the deposits have a fine crystal size ${ }^{14,49-50}$ which is supported by SEM analysis. The thickness of electrodeposited HKUST-1 on the GC electrode was estimated to be in the range of $\sim 240-330 \mathrm{~nm}$ using atomic force microscopy (AFM) coupled with WITech alpha 300SAR. The film was not uniform in thickness, which was revealed by scratching different areas on the GC electrode (not shown here). Fig. 3 (b-d) shows SEM images of HKUST-1 particles on a GC electrode. It can be seen that the electrodeposited MOF crystals are well defined in shape, i.e. a cuboctahedron (chamfered cubic) structure. Similar morphology for bulk powder is reported by tuning the synthesis procedure using n-dodecanoic acid (lauric acid) as a modulator. Gradual transformation from octahedron to cuboctahedral and cubic crystals of HKUST-1 were observed with different ratios of lauric acid to BTC ${ }^{51}$. Also, in our recent report, ethanol and methanol showed a significant effect on the morphology and crystal size of AlBTC (MIL-96) MOF ${ }^{18}$. The Bravais, Friedel, Donnay, and Harker (BFDH) law can be used to determine crystal shapes ${ }^{52}$. A crystal shape is formed by the coexistence of slower and faster growth facets. A cube is composed of six square facets of $\{100\}$, whereas an octahedron is surrounded by eight triangle facets of $\{111\}^{53}$. As the crystal grows, it gradually shapes the structure surrounded by the facets which have slower growth. A cuboctahedron is seen as an intermediate stage between a cube and an octahedron.

In the current study, the majority of crystals are in a cuboctahedron shape which may be attributed to an equal growth rate of the $\{100\}$ and $\{111\}^{53}$ facets, since faster growth of the $\{100\}$ compared to the $\{111\}$ results in octahedron shapes, and vice-versa for cubic crystals. $\mathrm{CTAB}$ acts as a structure directing agent, controlling the morphology and porosity of the deposited HKUST-1. Since CTAB can control the development of crystalline phases, this results in different morphologies, creating chamfered cubes, different to the usual octahedron shaped crystals. Such a transformation has been observed in the modulated solvothermal synthesis of HKUST-1 MOF owing to the concentration of the modulator/surfactant ${ }^{51}$. Moreover, the crystal size shown in Figure 3 is in the range of $800 \mathrm{~nm}$ to $2 \mu \mathrm{m}$ with an average crystal size of $855 \pm 65 \mathrm{~nm}$, which is less than previously reported bulk HKUST-1 ${ }^{16-17}$.

The change in morphology and smaller crystal size can be attributed to the presence of CTAB, and also $\mathrm{HCl}$, which slows down the growth of crystal formation, giving rise to gradual growth of cuboctahedron nanosized crystals ${ }^{46,54}$. To evaluate the porous structure of the HKUST-1 deposit, $\mathrm{N}_{2}$ adsorption/desorption is a useful technique to study the textural properties of porous 
materials, particularly MOFs. We have previously reported in detail the textural properties of MOFs (HKUST-1, UiO-66, ZIF-67 etc.). ${ }^{17,55}$ However, in this study, it is not possible to use $\mathrm{N}_{2}$ adsorption/desorption to estimate the surface area and porosity because the MOF material is deposited electrochemically in the form of a thin particle layer on the GC electrode, with the amount of material not enough for the analysis. However, SEM images (Figure 3c-d) provide sufficient information to estimate the porosity of the synthesized MOF. Interestingly, the presence of macropores in the crystals of HKUST-1 is obvious from SEM (Fig. 3c-d) due to the removal of surfactant through the activation process using water and ethanol in a 1:1 ratio ${ }^{6}$. Such pores can be very useful in post synthesis treatment to introduce functional and/or catalytically active materials for adsorption and catalytic/photocatalytic degradation of water contaminants $^{56-58}$. Fig. 3 (c-d) shows close-up images of the electrodeposited HKUST-1 crystals, clearly showing the presence of macropores $(>50 \mathrm{~nm})$. It can also be seen from Fig. 3 (c) that some of the crystals are broken during the removal of CTAB, leaving behind obvious large pores that are different from the inherent micro/mesopores of the HKUST-1.

\subsection{Electrochemical Characterization of HKUST-1 on a GC Electrode in an Ionic Liquid.}

Previous literature suggests that the electrodeposited MOF can be easily washed away in an aqueous medium after the synthesis ${ }^{21}$. However, in an ionic liquid, the MOF appears to be much more stable and well-adhered to the electrode surface. Thus, the HKUST-1 on GC electrode was first examined in a room temperature ionic liquid $\left(\left[\mathrm{C}_{2} \mathrm{mim}\right]\left[\mathrm{NTf}_{2}\right]\right)$ to observe any electroactivity. The dashed line in Figure 4 shows cyclic voltammetry (CV) of the HKUST -1 on GC electrode in the neat ionic liquid. No obvious oxidation or reduction features are present in the potential range of $-1.9 \mathrm{~V}$ to $+0.7 \mathrm{~V}$, with the exception of a small reductive impurity feature at $\sim-1.3 \mathrm{~V}$, which is commonly observed in imidazolium-type RTILs. As the potential is scanned more positively, no features are seen until $\sim+1.4 \mathrm{~V}$ and after which a broad anodic peak is observed, probably corresponding to decomposition of the MOF. A color change of the IL occurred at these potentials (colorless to greenish blue), suggesting that copper oxidation is likely taking place. The available potential window of $\sim-2.0 \mathrm{~V}$ to $+1.4 \mathrm{~V}$ is quite reasonable for the MOF modified electrode, allowing the opportunity to study the behavior of the thin-film towards redox processes that occur within this range, which will be investigated next. We note that the film of HKUST-1 remained stable on the GC electrode during hydrogen sensing experiments (described later) and did not visibly deteriorate over time if only scanned over the narrower potential window. 
A mixture of ferrocene $(\mathrm{Fc})$ and cobaltocenium hexafluorophosphate $\left(\mathrm{Cc}^{+}\left[\mathrm{PF}_{6}\right]^{-}\right)$was first dissolved into the ionic liquid to study the effect of the modified electrode on the formal potential and kinetics of these standard electrode reactions. These two compounds are considered relatively 'ideal' redox couples in non-aqueous solvents, and suggested for use as reference elecctrode materials in acetonitrile ${ }^{59}$. In RTILs, ferrocene is oxidized by one electron according to equation 1, and cobaltocenium is reduced by one electron according to equation $2^{60}$.

$$
\begin{aligned}
& \mathrm{Fc} \rightleftharpoons \mathrm{Fc}^{+}+e^{-} \\
& \mathrm{Cc}^{+}+e^{-} \rightleftharpoons \mathrm{Cc}
\end{aligned}
$$

Both reactions are chemically and electrochemically reversible (i.e. have relatively fast kinetics) in RTILs on conventional metallic electrodes ${ }^{61}$. Figure 4 shows CV for a mixture of $10 \mathrm{mM} \mathrm{Fc}+10 \mathrm{mM} \mathrm{Cc}^{+}$in $\left[\mathrm{C}_{2} \mathrm{mim}\right]\left[\mathrm{NTf}_{2}\right]$ on the HKUST-1/GC electrode (red line), and a comparison to the unmodified GC electrode (blue line), and an unmodified Pt electrode (green line). The formal potential (calculated as the mid-point potential) of the cobtalocenium/cobaltocene redox couple vs the ferrocene/ferrocenium redox couple is consistent over all the three surfaces $(\sim-1.34 \mathrm{~V})$, suggesting that the nature of the electrode surface does not influence the thermodynamics of the reactions. A peak-to-peak separation of $115 \mathrm{mV}$ for $\mathrm{Fc} / \mathrm{Fc}^{+}$and of $132 \mathrm{mV}$ for $\mathrm{Cc}^{+} / \mathrm{Cc}$ on the HKUST-1/GC electrode vs $105 \mathrm{mV}$ for $\mathrm{Fc} / \mathrm{Fc}^{+}$and $107 \mathrm{mV}$ for $\mathrm{Cc}^{+} / \mathrm{Cc}$ on the bare $\mathrm{GC}$ electrode suggest only a slight difference in the kinetics occurs as a result of electrode modification. However, a much wider peak-to-peak separation ( $280 \mathrm{mV}$ for $\mathrm{Fc} / \mathrm{Fc}^{+}$and $220 \mathrm{mV}$ for $\left.\mathrm{Cc}^{+} / \mathrm{Cc}\right)$ and a broader peak shape indicate that slower redox kinetics are occurring on platinum. The peak-to-peak separations increase with scan rate on all the surfaces. Overall, there is relatively little difference with regard to both peak shapes and positions for the HKUST-1/GC electrode compared to the bare GC electrode, except for a $\sim 20 \%$ increase in current on the forward sweep (oxidation of ferrocene), which could be due to an increase in the electroactive surface area as a result of the MOF thin-layer present on the surface. 


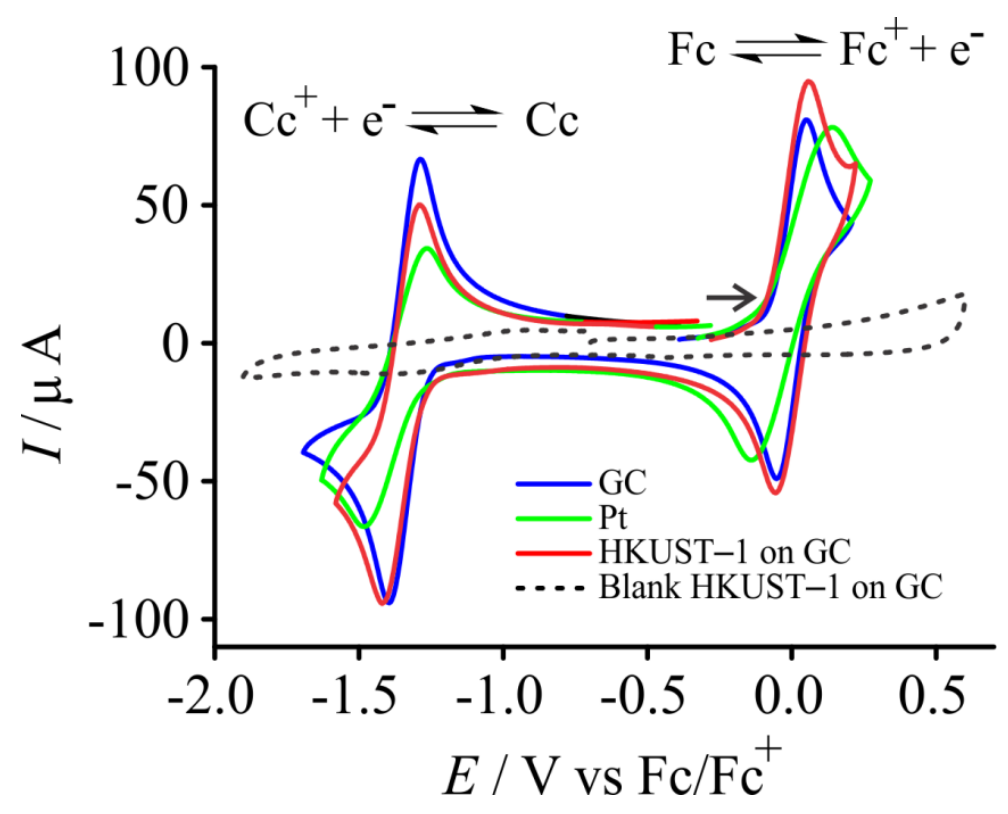

Figure 4: Cyclic voltammograms of a mixture of $10 \mathrm{mM}$ ferrocene and $10 \mathrm{mM}$ cobaltocenium hexafluorophosphate in $\left[\mathrm{C}_{2} \mathrm{mim}\right]\left[\mathrm{NTf}_{2}\right]$ at a scan rate of $100 \mathrm{mVs}^{-1}$ on bare GC (blue), bare $\mathrm{Pt}$ (green), and HKUST-1 on GC (red) electrodes. The dashed line is the response of the HKUST -1 on GC electrode in the absence of analyte species. All voltammograms have been shifted so that the midpoint of ferrocene/ferrocenium redox couple is at $0 \mathrm{~V}$ due to the use of a quasi-reference electrode.

3.3 Hydrogen Sensing on HKUST-1/GC Electrode. The HKUST-1/GC electrode was used for hydrogen sensing by oxidation in $\left[\mathrm{C}_{2} \mathrm{mim}\right]\left[\mathrm{NTf}_{2}\right]$. We have previously explained the need for electrochemical sensors for hydrogen and why RTILs are beneficial solvents for this application $^{6}$. Hydrogen is moderately soluble in this RTIL (saturated concentration of 4.2 $\mathrm{mM})^{62}$ and moves relatively fast compared to other solutes in RTILs (diffusion coefficient of $\left.5.5 \times 10^{-6} \mathrm{~cm}^{2} \mathrm{~s}^{-1}\right)^{62}$. The oxidation reaction on platinum can be written simply according to equation $3^{62-63}$, although the Pt surface and RTIL anion are likely to play a role in a more complex mechanism ${ }^{64}$. In this simplistic equation, the electrogenerated proton is likely to be solvated by one or more anions of the RTIL.

$$
\mathrm{H}_{2} \rightleftharpoons 2 \mathrm{H}^{+}+2 e^{-}
$$




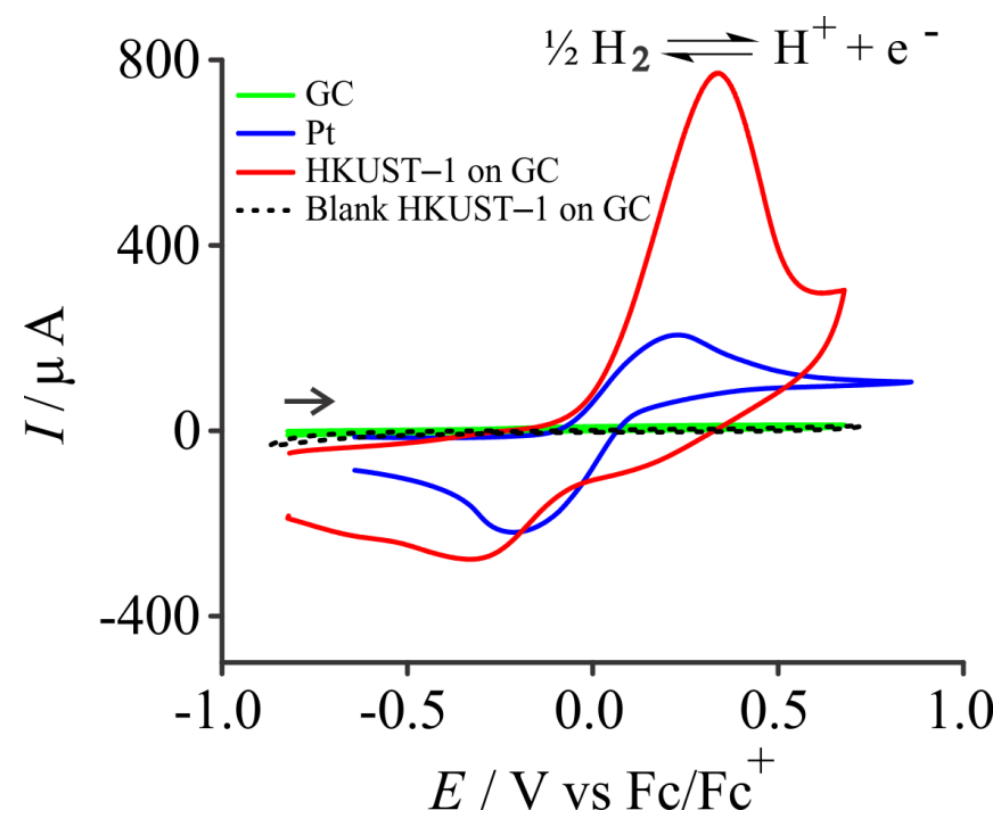

Figure 5: Cyclic voltammetry (CV) for $100 \%$ hydrogen oxidation on a GC (green), Pt (blue), and a HKUST -1 on GC (red) in $\left[\mathrm{C}_{2} \mathrm{mim}\right]\left[\mathrm{NTf}_{2}\right]$ at scan rate of $100 \mathrm{mVs}^{-1}$. The dashed line (black) is a blank voltammogram on the HKUST-1 on GC electrode in the absence of hydrogen. All voltammograms have been shifted so that the midpoint of the ferrocene/ferrocenium redox couple is at $0 \mathrm{~V}$ (corrected to cobaltocenium, which was added in-situ after the experiment).

Figure 5 shows cyclic voltammetry for the oxidation of a saturated solution of $\mathrm{H}_{2}$ at a scan rate of $100 \mathrm{mV} \mathrm{s}^{-1}$ on the three electrode surfaces. No response on the HKUST-1 on GC electrode occurs in the absence of hydrogen. Hydrogen oxidation is much more affected by the electrode material compared to ferrocene and cobaltocenium. It is apparent that there is no electroactivity towards hydrogen oxidation on the bare GC electrode within the potential range studied, but the Pt electrode shows a broad reversible oxidation wave, consistent with our previous work ${ }^{6}$. However, the HKUST-1 on GC electrode shows a surprisingly large current response and a partial adsorption-type CV shape where the current drop-off falls quite fast after the peak, indicative of thin-layer type behavior ${ }^{65}$. The maximum current is four times higher on the HKUST -1 on GC compared to the Pt electrode, demonstrating clearly and significantly a catalytic activity towards hydrogen oxidation. It is unlikely that this current enhancement is due to an increase in surface area, as this was not observed for ferrocene in Figure 4. The reverse peak in Figure 5 (reduction of the solvated proton) shows a similar current for both the surfaces, despite the four-fold enhancement of oxidation peak current, consistent with the expected electrochemical behavior in a porous thin-layer ${ }^{65}$. Interestingly, the HKUST-1 modified electrode outperforms a macroporous Pt electrode reported in our previous work ${ }^{6}$. 
The potentials in Figure 5 have been shifted so that the mid-point potential of the $\mathrm{Fc} / \mathrm{Fc}^{+}$redox couple is zero, with details given in the experimental section. The onset of hydrogen oxidation is similar for the HKUST-1 on GC electrode compared to platinum, however, the peak potential is $\sim 290 \mathrm{mV}$ more positive on HKUST -1 on GC electrode. The midpoint potentials are $+0.22 \mathrm{~V}$ on Pt compared to $+0.33 \mathrm{~V}$ on HKUST -1 on GC, suggesting that the kinetics of the reaction on the HKUST-1 on GC electrode are not quite as fast as that on Pt, but is significantly faster than that on the bare GC electrode, where no oxidation peak was observed. Thus, the modified electrode shows an excellent catalytic activity compared to the bare GC electrode.

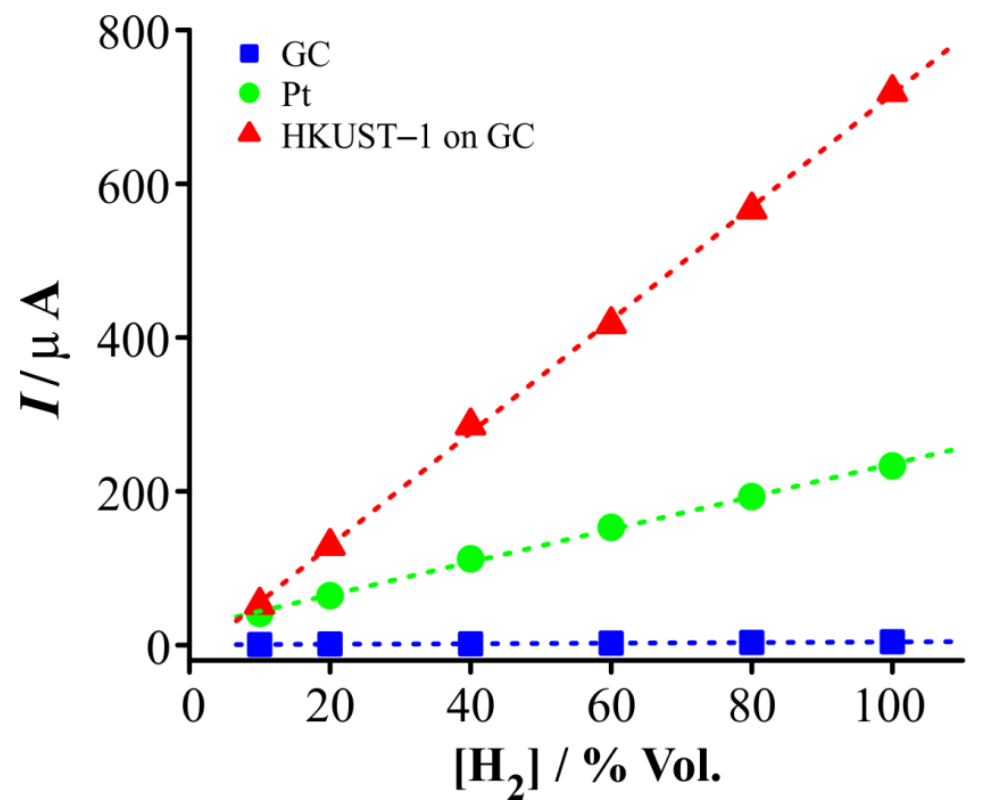

Figure 6. Comparison of calibration plots (absolute current vs concentration) for hydrogen oxidation in $\left[\mathrm{C}_{2} \mathrm{mim}\right]\left[\mathrm{NTf}_{2}\right]$ on a bare GC, Pt and HKUST-1 on GC electrodes.

In order to investigate the analytical response for HKUST -1 on the GC electrode $v s$ Pt and GC electrodes, cyclic voltammetry for different concentrations of hydrogen were examined from $10-100 \% \mathrm{H}_{2}$. Figure 6 shows a comparison of calibration plot for absolute current $v s$ different concentrations of hydrogen in $\left[\mathrm{C}_{2} \mathrm{mim}\right]\left[\mathrm{NTf}_{2}\right]$ when the current had stabilised (after ca. 20 min between each concentration change). The HKUST-1 on GC electrode shows the highest sensitivity (gradient $7.4 \mu \mathrm{A} / \% \mathrm{H}_{2}$ ) compared with the Pt electrode (gradient $2.1 \mu \mathrm{A} / \% \mathrm{H}_{2}$ ). The higher sensitivity of the HKUST-1 on GC electrode can be attributed to a larger electroactive surface area, likely due to the greater micro and nano porosity of the electrodeposited MOF compared to the bare Pt (polycrystalline) electrode. The bare GC electrode has negligible 
sensitivity (gradient $0.04 \mu \mathrm{A} / \% \mathrm{H}_{2}$ ) due to its very poor activity for hydrogen oxidation over this potential range.

It was noted that the current for hydrogen oxidation on the MOF modified electrode took longer to stabilize compared to the other surfaces. Therefore, a study was conducted to monitor the peak current response over time exposed to $100 \%$ hydrogen gas. Figure 7 shows a comparison of current responses on the three electrode surfaces as hydrogen gas is introduced. The equilibration time for the partitioning step is relatively slow due to the larger volume of RTIL solvent employed for the experiments $(\sim 300 \mu \mathrm{L})$. We note that this could be improved in future experiments by employing planar electrodes and much smaller volumes of RTILs (e.g. $\sim 3 \mu \mathrm{L}$ ), which would also reduce the cost of the sensor ${ }^{66}$. The currents were recorded at $100 \mathrm{~s}$ intervals up to a total of $2500 \mathrm{~s}$. The $\mathrm{GC}$ electrode shows no appreciable response over the whole time period, whereas the Pt electrode shows a steadily increasing current that plateaus at $\sim 190 \mu \mathrm{A}$ after $700 \mathrm{~s}$. A steady increase in the current for the HKUST-1 electrode is observed up to a maximum current of $\sim 770 \mu \mathrm{A}$ at $700 \mathrm{~s}$, after which the current slowly decreases until it levels off at around $500 \mu \mathrm{A}$. This behavior was consistent in several repeat runs, and likely corresponds to the adsorption and trapping of hydrogen within the pores of the MOF; the current then decreases slightly each time upon application of a potential once it is equilibrated.

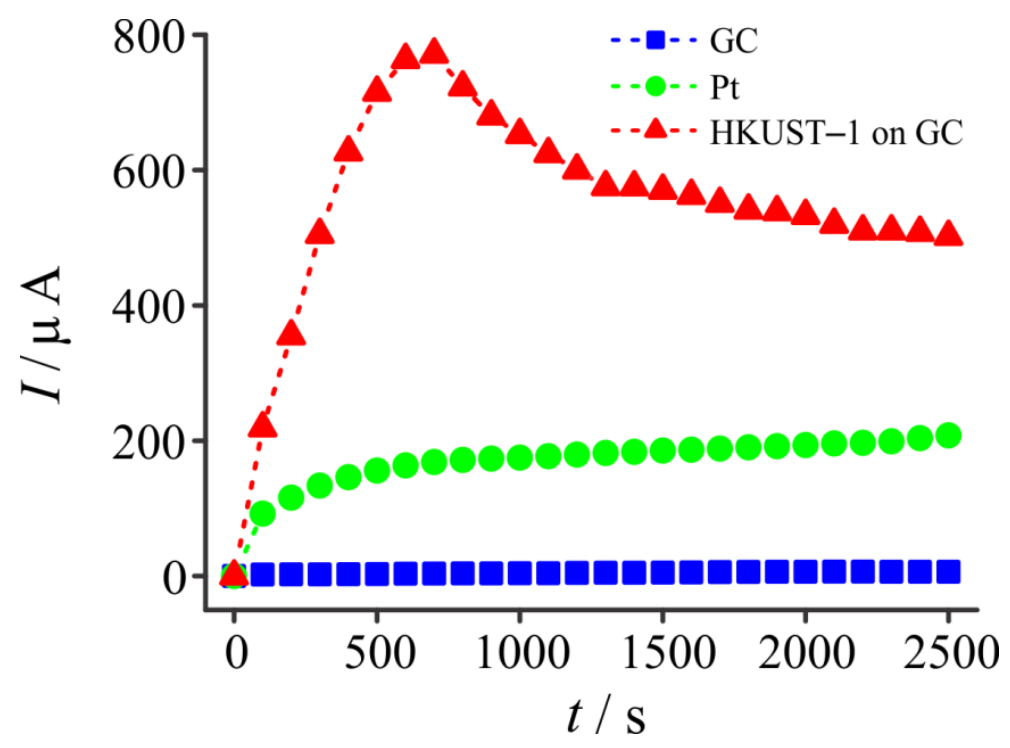

Figure 7. Comparison of oxidation current vs time for $100 \%$ hydrogen $\left(100 \mathrm{mV} \mathrm{s}^{-1}\right)$ on a GC (blue), Pt (green), and HKUST-1 on GC (red) electrodes in the RTIL [ $\mathrm{C}_{2}$ mim] $\left[\mathrm{NTf}_{2}\right]$. 
After hydrogen sensing experiments, it required more than $12 \mathrm{~h}$ of nitrogen flushing at a high flow rate to diminish the hydrogen signal to zero, supporting the suggestion of hydrogen adsorption within the MOF pores, and strikingly similar to our previous findings on a porous Pt electrode ${ }^{6}$. Based on these observations, it is expected that these materials may also provide a promising pathway for hydrogen storage applications, in addition to other electrochemical applications.

\section{Conclusions}

The electrochemical synthesis of HKUST -1 on GC resulted in macroporous particles on glassy carbon electrodes. Room temperature ionic liquids were employed as an electrolyte for the electrochemical sensing of hydrogen. The MOF modified electrode exhibited significantly enhanced activity towards the detection of hydrogen gas in the RTIL $\left[\mathrm{C}_{2} \operatorname{mim}\right]\left[\mathrm{NTf}_{2}\right]$. The response of HKUST-1/GC electrode in the presence of $\left[\mathrm{C}_{2} \mathrm{mim}\right]\left[\mathrm{NTf}_{2}\right]$ was four times higher than a pure Pt electrode under the similar conditions. Hydrogen appeared to become trapped in the pores of the MOF structures. This study highlights the successful application of costeffective pristine MOF thin-films in combination with RTILs in low-cost gas sensing applications.

\section{Acknowledgements}

DSS thanks the Australian Research Council (ARC) for funding through a Future Fellowship [FT170100315]. SW also thanks the Australian Research Council for funding (DP170104264). The authors acknowledge the use of equipment of the Curtin University Electron Microscope Facility, which is partially funded by the University, State and Commonwealth Governments of Australia.

\section{References}

1. Korotcenkov, G.; Han, S. D.; Stetter, J. R., Review of Electrochemical Hydrogen Sensors. Chem. Rev. 2009, 109 (3), 1402-1433.

2. Hübert, T.; Boon-Brett, L.; Black, G.; Banach, U., Hydrogen sensors - A review. Sens. Actuators B: Chem. 2011, 157 (2), 329-352.

3. Weber, M.; Kim, J. H.; Lee, J. H.; Kim, J. Y.; Iatsunskyi, I.; Coy, E.; Drobek, M.; Julbe, A.; Bechelany, M.; Kim, S. S., High-Performance Nanowire Hydrogen Sensors by Exploiting 
the Synergistic Effect of Pd Nanoparticles and Metal-Organic Framework Membranes. ACS Appl. Mater. Interfaces 2018. 10, 34765-34773.

4. Huang, L.; Zhang, Z.; Li, Z.; Chen, B.; Ma, X.; Dong, L.; Peng, L. M., Multifunctional graphene sensors for magnetic and hydrogen detection. ACS Appl. Mater. Interfaces 2015, 7 (18), 9581-8.

5. Ge, M.; Hussain, G.; Hibbert, D. B.; Silvester, D. S.; Zhao, C., Ionic Liquid-based Microchannels for Highly Sensitive and Fast Amperometric Detection of Toxic Gases. Electroanalysis 2019, 31 (1), 66-74.

6. Hussain, G.; Sofianos, M. V.; Lee, J.; Gibson, C.; Buckley, C. E.; Silvester, D. S., Macroporous platinum electrodes for hydrogen oxidation in ionic liquids. Electrochem. Commun. 2018, 86, 43-47.

7. Hussain, G.; O'Mullane, A. P.; Silvester, D. S., Modification of Microelectrode Arrays with High Surface Area Dendritic Platinum 3D Structures: Enhanced Sensitivity for Oxygen Detection in Ionic Liquids. Nanomaterials (Basel) 2018, 8 (9), 735.

8. Hussain, G.; Aldous, L.; Silvester, D. S., Preparation of platinum-based cauliflower microarrays' for enhanced ammonia gas sensing. Anal. Chim. Acta 2019, 1048, 12-21.

9. Sturluson, A.; Sousa, R.; Zhang, Y.; Huynh, M. T.; Laird, C.; York, A. H. P.; Silsby, C.; Chang, C. H.; Simon, C. M., Curating Metal-Organic Frameworks To Compose Robust Gas Sensor Arrays in Dilute Conditions. ACS Appl. Mater. Interfaces 2020, 12 (5), 6546-6564. 10. Bagheri, M.; Masoomi, M. Y., Sensitive Ratiometric Fluorescent Metal-Organic Framework Sensor for Calcium Signaling in Human Blood Ionic Concentration Media. ACS Appl. Mater. Interfaces 2020, 12 (4), 4625-4631.

11. Wang, H.-L.; Yeh, H.; Li, B.-H.; Lin, C.-H.; Hsiao, T.-C.; Tsai, D.-H., ZirconiumBased Metal-Organic Framework Nanocarrier for the Controlled Release of Ibuprofen. ACS Appl. Nano Mater. 2019, 2 (6), 3329-3334.

12. Wang, Y.-S.; Liao, J.-L.; Li, Y.-S.; Chen, Y.-C.; Li, J.-H.; Ho, W. H.; Chiang, W.-H.; Kung, C.-W., Zirconium-Based Metal-Organic Framework Nanocomposites Containing Dimensionally Distinct Nanocarbons for Pseudocapacitors. ACS Appl. Nano Mater. 2020, DOI: $10.1021 /$ acsanm.9b02297.

13. Stylianou, K. C.; Warren, J. E.; Chong, S. Y.; Rabone, J.; Bacsa, J.; Bradshaw, D.; Rosseinsky, M. J., $\mathrm{CO}_{2}$ selectivity of a $1 \mathrm{D}$ microporous adenine-based metal-organic framework synthesised in water. Chem. Commun. 2011, 47 (12), 3389-3391.

14. Sun, Y.; Zhou, H. C., Recent progress in the synthesis of metal-organic frameworks. Sci. Technol. Adv. Mater. 2015, 16 (5), 054202. 
15. Zhang, W.; Kauer, M.; Guo, P.; Kunze, S.; Cwik, S.; Muhler, M.; Wang, Y.; Epp, K.; Kieslich, G.; Fischer, R. A., Impact of Synthesis Parameters on the Formation of Defects in HKUST-1. Eur. J. Inorg. Chem. 2017, 2017 (5), 925-931.

16. Azhar, M. R.; Abid, H. R.; Sun, H.; Periasamy, V.; Tade, M. O.; Wang, S., Excellent performance of copper based metal organic framework in adsorptive removal of toxic sulfonamide antibiotics from wastewater. J. Colloid. Interface Sci. 2016, 478, 344-52.

17. Azhar, M. R.; Abid, H. R.; Sun, H.; Periasamy, V.; Tade, M. O.; Wang, S., One-pot synthesis of binary metal organic frameworks (HKUST-1 and UiO-66) for enhanced adsorptive removal of water contaminants. J. Colloid Interface Sci. 2017, 490, 685-694.

18. Azhar, M. R.; Abid, H. R.; Tade, M. O.; Periasamy, V.; Sun, H.; Wang, S., Cascade applications of robust MIL-96 metal organic frameworks in environmental remediation: Proof of concept. Chem. Eng. J. 2018, 341, 262-271.

19. Alizadeh, S.; Nematollahi, D., Electrochemically Assisted Self-Assembly Technique for the Fabrication of Mesoporous Metal-Organic Framework Thin Films: Composition of 3D Hexagonally Packed Crystals with 2D Honeycomb-like Mesopores. J. Am. Chem. Soc. 2017, 139 (13), 4753-4761.

20. Stassen, I.; Styles, M.; Grenci, G.; Gorp, H. V.; Vanderlinden, W.; Feyter, S. D.; Falcaro, P.; Vos, D. D.; Vereecken, P.; Ameloot, R., Chemical vapour deposition of zeolitic imidazolate framework thin films. Nat. Mater. 2016, 15 (3), 304-310.

21. Campagnol, N.; Van Assche, T. R. C.; Li, M.; Stappers, L.; Dincă, M.; Denayer, J. F. M.; Binnemans, K.; De Vos, D. E.; Fransaer, J., On the electrochemical deposition of metalorganic frameworks. J. Mater. Chem. A 2016, 4 (10), 3914-3925.

22. Stassen, I.; Styles, M.; Van Assche, T.; Campagnol, N.; Fransaer, J.; Denayer, J.; Tan, J.-C.; Falcaro, P.; De Vos, D.; Ameloot, R., Electrochemical Film Deposition of the Zirconium Metal-Organic Framework UiO-66 and Application in a Miniaturized Sorbent Trap. Chem. Mater. 2015, 27 (5), 1801-1807.

23. Crawford, S. E.; Kim, K.-J.; Yu, Y.; Ohodnicki, P. R., Rapid, Selective, Ambient Growth and Optimization of Copper Benzene-1,3,5-Tricarboxylate ( $\mathrm{Cu}-\mathrm{BTC})$ Metal-Organic Framework Thin Films on a Conductive Metal Oxide. Crys.Growth Des. 2018, 18 (5), 29242931.

24. Li, M.; Dincă, M., Selective formation of biphasic thin films of metal-organic frameworks by potential-controlled cathodic electrodeposition. Chem. Sci. 2014, 5 (1), 107111. 
25. Yang, H. M.; Song, X. L.; Yang, T. L.; Liang, Z. H.; Fan, C. M.; Hao, X. G., Electrochemical synthesis of flower shaped morphology MOFs in an ionic liquid system and their electrocatalytic application to the hydrogen evolution reaction. $R S C A d v . \mathbf{2 0 1 4}, 4$ (30), 15720-15726.

26. Talin, A. A.; Centrone, A.; Ford, A. C.; Foster, M. E.; Stavila, V.; Haney, P.; Kinney, R. A.; Szalai, V.; El Gabaly, F.; Yoon, H. P.; Leonard, F.; Allendorf, M. D., Tunable electrical conductivity in metal-organic framework thin-film devices. Science 2014, 343 (6166), 66-69.

27. Xu, Y.; Li, Q.; Xue, H.; Pang, H., Metal-organic frameworks for direct electrochemical applications. Coord. Chem. Rev. 2018, 376, 292-318.

28. Vakili, R.; Xu, S.; Al-Janabi, N.; Gorgojo, P.; Holmes, S. M.; Fan, X., Microwaveassisted synthesis of zirconium-based metal organic frameworks (MOFs): Optimization and gas adsorption. Microporous Mesoporous Mater. 2018, 260, 45-53.

29. Al-Janabi, N.; Hill, P.; Torrente-Murciano, L.; Garforth, A.; Gorgojo, P.; Siperstein, F.; Fan, X., Mapping the Cu-BTC metal-organic framework (HKUST-1) stability envelope in the presence of water vapour for $\mathrm{CO}_{2}$ adsorption from flue gases. Chem. Eng. J. 2015, 281, 669677.

30. Ji, L.; Hao, J.; Wu, K.; Yang, N., Potential-Tunable Metal-Organic Frameworks: Electrosynthesis, Properties, and Applications for Sensing of Organic Molecules. J. Phys. Chem. C 2019, 123 (4), 2248-2255.

31. Worrall, S. D.; Mann, H.; Rogers, A.; Bissett, M. A.; Attfield, M. P.; Dryfe, R. A. W., Electrochemical deposition of zeolitic imidazolate framework electrode coatings for supercapacitor electrodes. Electrochim. Acta 2016, 197, 228-240.

32. Sun, L. B.; Li, J. R.; Park, J.; Zhou, H. C., Cooperative template-directed assembly of mesoporous metal-organic frameworks. J. Am. Chem. Soc. 2012, 134 (1), 126-9.

33. Ling, P.; Lei, J.; Zhang, L.; Ju, H., Porphyrin-encapsulated metal-organic frameworks as mimetic catalysts for electrochemical DNA sensing via allosteric switch of hairpin DNA. Anal. Chem. 2015, 87 (7), 3957-3963.

34. Wang, L.; Meng, T.; Liang, L.; Sun, J.; Wu, S.; Wang, H.; Yang, X.; Zhang, Y., Fabrication of amine-functionalized metal-organic frameworks with embedded palladium nanoparticles for highly sensitive electrochemical detection of telomerase activity. Sens. Actuators B: Chem. 2019, 278, 133-139.

35. Anik, U.; Timur, S.; Dursun, Z., Metal organic frameworks in electrochemical and optical sensing platforms: a review. Mikrochim. Acta 2019, 186 (3), 196. 
36. Yao, X. Y.; Wang, Q.; Liu, Q.; Pang, M.; Du, X. M.; Zhao, B.; Li, Y.; Ruan, W. J., Ultrasensitive Assay of Alkaline Phosphatase Based on the Fluorescent Response Difference of the Metal-Organic Framework Sensor. ACS Omega 2020, 5 (1), 712-717.

37. Kempahanumakkagari, S.; Vellingiri, K.; Deep, A.; Kwon, E. E.; Bolan, N.; Kim, K.H., Metal-organic framework composites as electrocatalysts for electrochemical sensing applications. Coord. Chem. Rev. 2018, 357, 105-129.

38. Hussain, G.; Silvester, D. S., Detection of sub-ppm Concentrations of Ammonia in an Ionic Liquid: Enhanced Current Density Using "Filled" Recessed Microarrays. Anal. Chem. 2016, 88 (24), 12453-12460.

39. Schroder, U.; Wadhawan, J. D.; Compton, R. G.; Marken, F.; Suarez, P. A. Z.; Consorti, C. S.; de Souza, R. F.; Dupont, J., Water-induced accelerated ion diffusion: voltammetric studies in 1-methyl-3-[2,6-(S)-dimethylocten-2-yl]imidazolium tetrafluoroborate, 1-butyl-3methylimidazolium tetrafluoroborate and hexafluorophosphate ionic liquids. New J. Chem. 2000, 24 (12), 1009-1015.

40. Murugappan, K.; Lee, J.; Silvester, D. S., Comparative study of screen printed electrodes for ammonia gas sensing in ionic liquids. Electrochem. Commun. 2011, 13 (12), $1435-1438$.

41. Lee, J.; Murugappan, K.; Arrigan, D. W. M.; Silvester, D. S., Oxygen reduction voltammetry on platinum macrodisk and screen-printed electrodes in ionic liquids: Reaction of the electrogenerated superoxide species with compounds used in the paste of Pt screen-printed electrodes? Electrochim. Acta 2013, 101, 158-168.

42. Lin, S.; Song, Z.; Che, G.; Ren, A.; Li, P.; Liu, C.; Zhang, J., Adsorption behavior of metal-organic frameworks for methylene blue from aqueous solution. Microporous and Mesoporous Mater. 2014, 193, 27-34.

43. Duke, A. S.; Dolgopolova, E. A.; Galhenage, R. P.; Ammal, S. C.; Heyden, A.; Smith, M. D.; Chen, D. A.; Shustova, N. B., Active Sites in Copper-Based Metal-Organic Frameworks: Understanding Substrate Dynamics, Redox Processes, and Valence-Band Structure. J. Phys. Chem. C 2015, 119 (49), 27457-27466.

44. Ananth, A.; Dharaneedharan, S.; Heo, M.-S.; Mok, Y. S., Copper oxide nanomaterials: Synthesis, characterization and structure-specific antibacterial performance. Chem. Eng. J. 2015, 262, 179-188.

45. Nijem, N.; Bluhm, H.; Ng, M. L.; Kunz, M.; Leone, S. R.; Gilles, M. K., Cu ${ }^{+}$in HKUST-1: selective gas adsorption in the presence of water. Chem. Commun. 2014, 50 (70), 10144-10147. 
46. Ji, L.; Wang, J.; Wu, K.; Yang, N., Tunable Electrochemistry of Electrosynthesized Copper Metal-Organic Frameworks. Adv. Funct. Mater. 2018, 28 (13), 1706961.

47. Senthil Kumar, R.; Senthil Kumar, S.; Anbu Kulandainathan, M., Efficient electrosynthesis of highly active $\mathrm{Cu}_{3}(\mathrm{BTC})_{2}-\mathrm{MOF}$ and its catalytic application to chemical reduction. Microporous Mesoporous Mater. 2013, 168, 57-64.

48. Yakovenko, A. A.; Reibenspies, J. H.; Bhuvanesh, N.; Zhou, H.-C., Generation and applications of structure envelopes for porous metal-organic frameworks. J. Appl. Crystallogr. 2013, 46 (2), 346-353.

49. Wahiduzzaman; Allmond, K.; Stone, J.; Harp, S.; Mujibur, K., Synthesis and Electrospraying of Nanoscale MOF (Metal Organic Framework) for High-Performance $\mathrm{CO}_{2}$ Adsorption Membrane. Nanoscale Res. Lett. 2017, 12 (1), 6-12.

50. Seoane, B.; Dikhtiarenko, A.; Mayoral, A.; Tellez, C.; Coronas, J.; Kapteijn, F.; Gascon, J., Metal organic framework synthesis in the presence of surfactants: towards hierarchical MOFs? CrystEngComm 2015, 17 (7), 1693-1700.

51. Umemura, A.; Diring, S.; Furukawa, S.; Uehara, H.; Tsuruoka, T.; Kitagawa, S., Morphology design of porous coordination polymer crystals by coordination modulation. $J$. Am. Chem. Soc. 2011, 133 (39), 15506-15513.

52. Donnay, J. D. H. H., David, A new law of crystal morphology extending the law of Bravais. Am. Mineral. 1937, 22, 446-467.

53. Angerstein-Kozlowska, H.; Conway, B. E.; Hamelin, A.; Stoicoviciu, L., Elementary steps of electrochemical oxidation of single-crystal planes of Au Part II. A chemical and structural basis of oxidation of the (111) plane. J. Electroanal. Chem. Interfacial Electrochem. 1987, $228(1), 429-453$.

54. Guo, Y.-N.; Li, Y.; Zhi, B.; Zhang, D.; Liu, Y.; Huo, Q., Effect of cationic surfactants on structure and morphology of mesostructured MOFs. RSC Adv. 2012, 2 (12), 5424.

55. Azhar, M. R.; Abid, H. R.; Periasamy, V.; Sun, H.; Tade, M. O.; Wang, S., Adsorptive removal of antibiotic sulfonamide by UiO-66 and ZIF-67 for wastewater treatment. J. Colloid Interface Sci. 2017, 500, 88-95.

56. Ahmed, A.; Hodgson, N.; Barrow, M.; Clowes, R.; Robertson, C. M.; Steiner, A.; McKeown, P.; Bradshaw, D.; Myers, P.; Zhang, H., Macroporous metal-organic framework microparticles with improved liquid phase separation. J. Mater. Chem. A 2014, 2 (24), 9085 9090 .

57. Liang, R.; Luo, S.; Jing, F.; Shen, L.; Qin, N.; Wu, L., A simple strategy for fabrication of Pd@MIL-100(Fe) nanocomposite as a visible-light-driven photocatalyst for the treatment 
of pharmaceuticals and personal care products (PPCPs). Appl. Catal. B: Environ. 2015, 176$177,240-248$.

58. Liu, Q.; Duan, X.; Sun, H.; Wang, Y.; Tade, M. O.; Wang, S., Size-Tailored Porous Spheres of Manganese Oxides for Catalytic Oxidation via Peroxymonosulfate Activation. $J$. Phys. Chem. C 2016, 120 (30), 16871-16878.

59. Gritzner, G.; Kůta, J., Recommendations on reporting electrode potentials in nonaqueous solvents: IUPC commission on electrochemistry. Electrochim. Acta 1984, 29 (6), 869-873.

60. Rogers, E. I.; Silvester, D. S.; Poole, D. L.; Aldous, L.; Hardacre, C.; Compton, R. G., Voltammetric Characterization of the Ferrocene|Ferrocenium and Cobaltocenium|Cobaltocene Redox Couples in RTILs. J. Phys. Chem. C 2008, 112 (7), 2729-2735.

61. Fietkau, N.; Clegg, A. D.; Evans, R. G.; Villagran, C.; Hardacre, C.; Compton, R. G., Electrochemical rate constants in room temperature ionic liquids: the oxidation of a series of ferrocene derivatives. Chemphyschem 2006, 7 (5), 1041-1045.

62. Silvester, D. S.; Ward, K. R.; Aldous, L.; Hardacre, C.; Compton, R. G., The electrochemical oxidation of hydrogen at activated platinum electrodes in room temperature ionic liquids as solvents. J. Electroanal. Chem. 2008, 618 (1-2), 53-60.

63. Silvester, D. S.; Aldous, L.; Hardacre, C.; Compton, R. G., An Electrochemical Study of the Oxidation of Hydrogen at Platinum Electrodes in Several Room Temperature Ionic Liquids. J. Phys. Chem. B 2007, 111 (18), 5000-5007.

64. Tang, Y.; Lin, L.; Kumar, A.; Guo, M.; Sevilla, M.; Zeng, X., Hydrogen Electrooxidation in Ionic Liquids Catalyzed by the NTf2 Radical. J. Phys. Chem. C 2017, 121 (9), 5161-5167.

65. Streeter, I.; Wildgoose, G. G.; Shao, L.; Compton, R. G., Cyclic voltammetry on electrode surfaces covered with porous layers: An analysis of electron transfer kinetics at single-walled carbon nanotube modified electrodes. Sens. and Actuators B 2008, 133 (2), 462 466.

66. Silvester, D. S., New innovations in ionic liquid-based miniaturised amperometric gas sensors. Curr. Opin. Electrochem. 2019, 15, 7-17. 


\section{TOC}

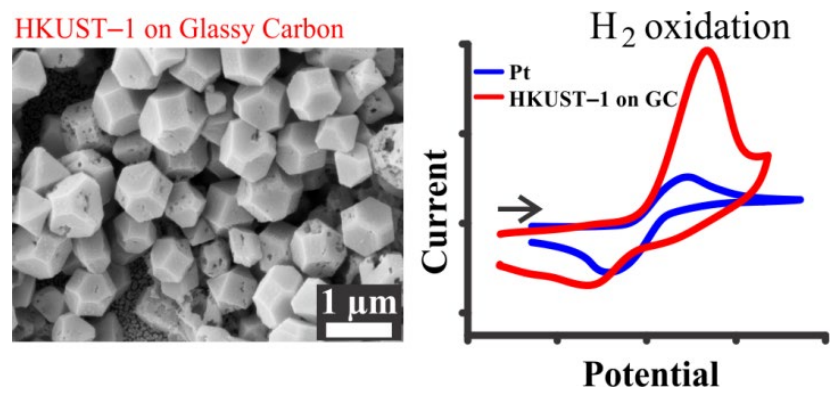

